\title{
A Contribution to the Study of the Chromosomes in Some Asiatic Mammals ${ }^{1}$
}

\author{
By \\ Sajiro Makino \\ Zoological Institute, Hokkaido University, Sapporo \\ Received December 5, 1951
}

About a decade has elapsed since the present author undertook a comparative study of chromosomes in mammals commonly obtainable in Japan and adjacent localities. He has endeavoured to make as broad a survey of Eutheria as possible, with consideration on the evolutional significance of the chromosomes. During the past years his own investigations have extended to the chromosomes of 49 species representative of eight Eutherian orders. The results of these investigations have been reported, except for a few unpublished ones, in 25 papers already published or now in press. The reports cover for each species, the cytological characters involving the chromosome number, the constitution of karyotype and the sex-chromosome mechanism together with their meiotic behavior. In the present paper will be reviewed summarily the data now at hand through the author's own studies, with particular reference to the taxonomical implication of certain cytological characters.

It is the author's pleasant duty to acknowledge here his very great indebtedness to Emeritus Professor Kan Oguma, now the director of the National Institute of Genetics, Mishima, under whose guidance the studies hitherto published were carried out and who has lent almost continuous encouragement with many of valuable advice during the course of the work.

\section{The number of chromosomes}

The species under study and the number of chromosomes established, respectively, are listed in Table 1, together with some remarks on the sex chromosomes, the locality where the material animal was collected or secured, and reference to each paper with the date of publication. As indicated in Table 1, the author's chromosome survey has extended to 49 Eutherian species covering eight orders, which represent 1 species of Edentata, 1 species of Cetacea, 2 species of Chiroptera, 25 species of Rodentia, 7 species of Carnivora, 8 species of Artiodactyla, 3 species of Perissodactyla, and 2 species of Primates. The results of these

1 Contribution No. 264 from the Zoological Institute, Faculty of Science, Hokkaido University, Sapporo, Japan.

Aided by the grants from the Scientific Research Fund and the Developmental Scientific Research Fund, both out of the Ministry of Education. 
Table 1. The species under study and the number of chromosomes established.

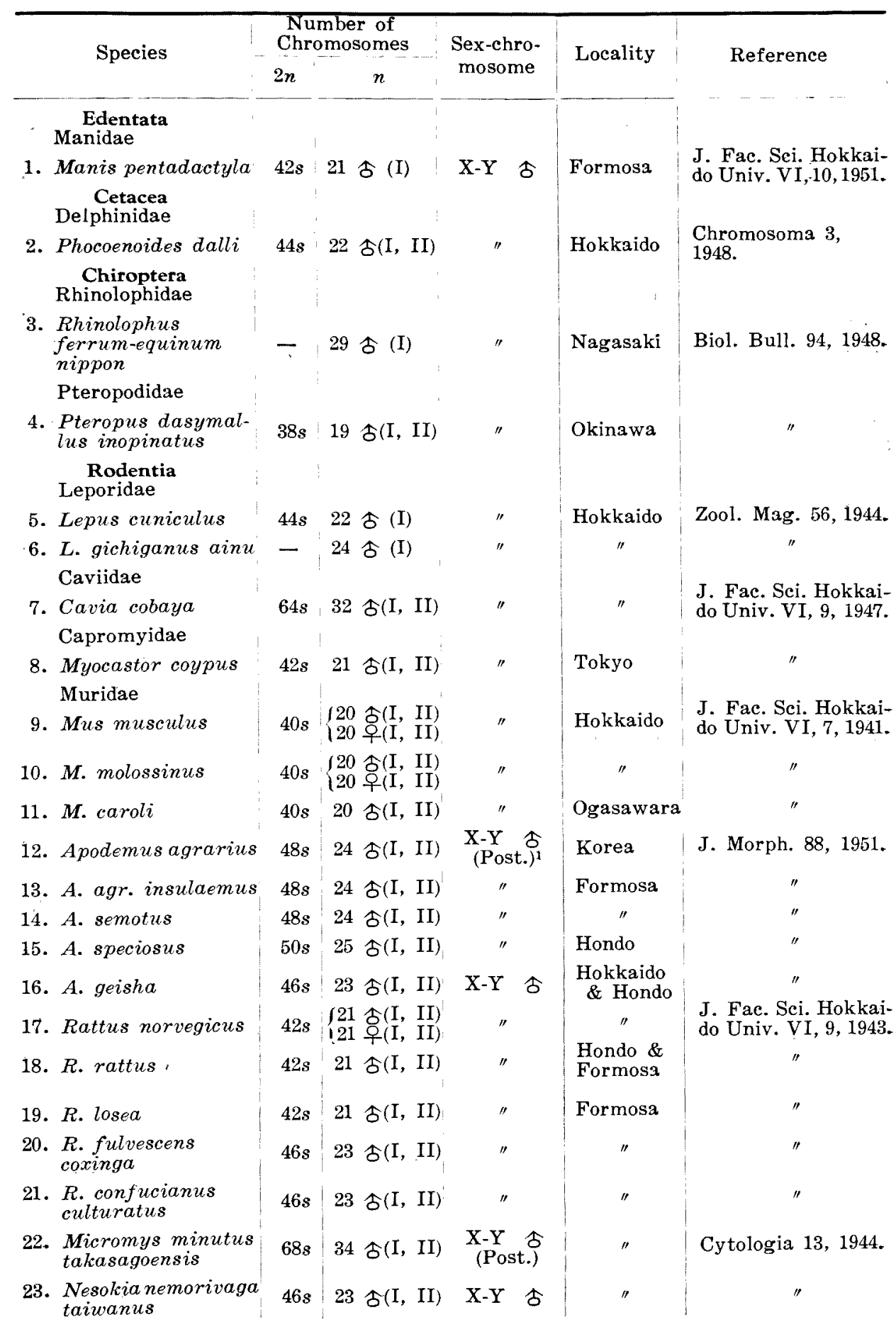




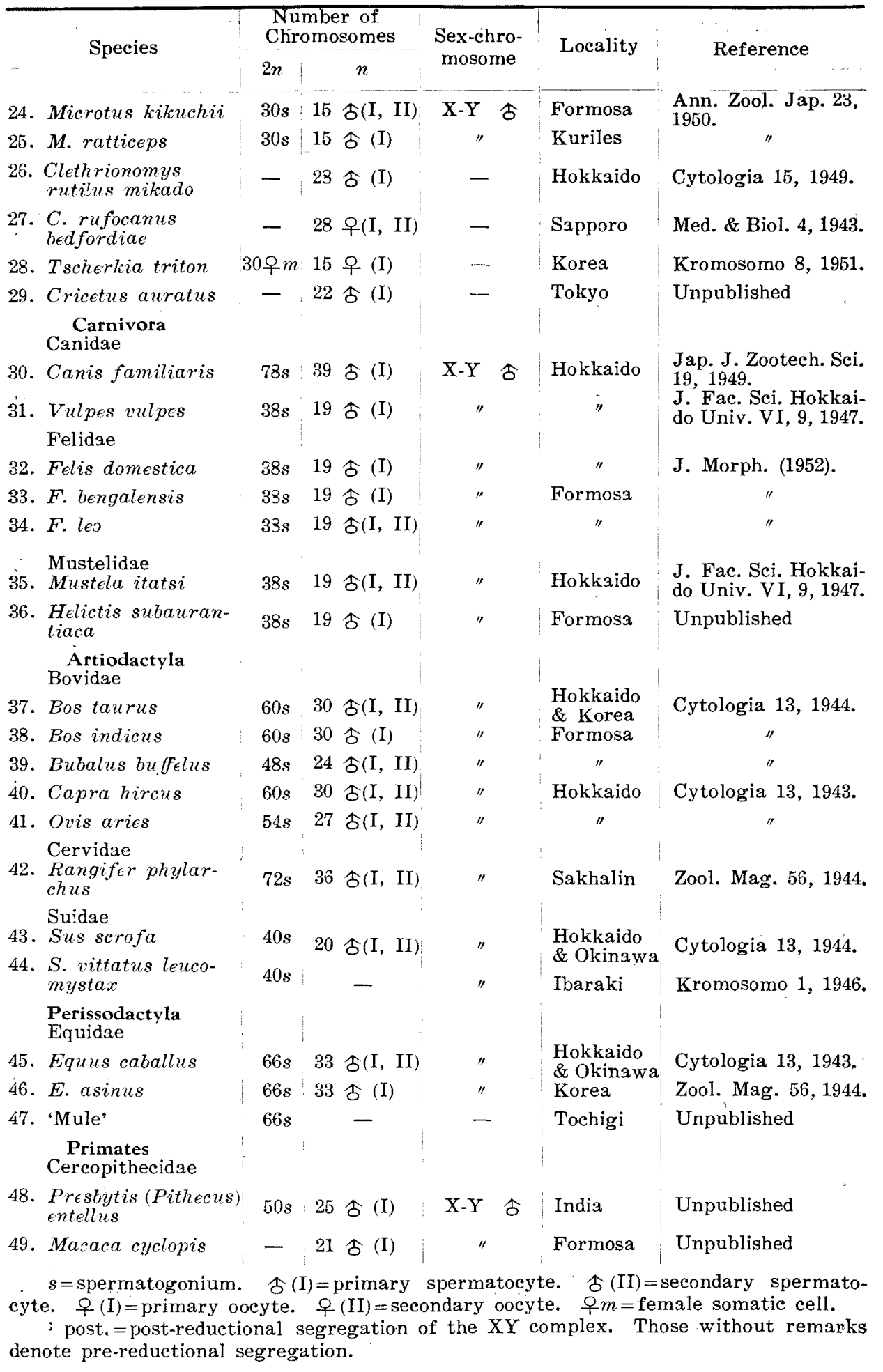


studies demonstrate that there is a striking diversity in the number of chromosomes of the species studied. The range is from 30 in three species of voles, Microtus kikuchii, M. ratticeps and Tscherkia triton to 78 in the dog, Canis familiaris. Between these extremes various chromosome numbers are represented. Despite such a wide divergence in chromosome number, there is yet the retention of the same or nearly equal number by a group of species whose close relationship is taxonomically established; this situation obtains among the species of the Muridae, Felidae, Mustelidae, Bovidae, Suidae and Equidae. Painter (1925), ${ }^{1}$ basing his considerations on the results of his studies on the mammalian chromosomes, deduced that the chromosome number 48 seems to be typical and is probably the basal number for mammals. The data newly obtained by the author clearly indicate that the occurrence of 48 chromosomes is very rare in mammals. For instance, the chromosome number 48 was proved to exist in only four out of 48 species studied by the present author-to wit-Buballus buffelus of the Artiodactyla, and Apodemus agrarius, A. semotus and Lepus gichiganus ainu of the Rodentia. Thus the chromosome number 48 can no longer be regarded as the basal number. Recently, Matthey (1948) ${ }^{2}$ attempted to arrange the fundamental chromosome number of mammals by equating the diverse numerical types through a simple Robertsonian relation (the evolutionary equivalence of 1 atelomitic to 2 telomitic chromosomes). But such an attempt is in general impossible. The numerical as well as morphological diversities of the chromosome complements as now known in mammals are too great to be accounted for by such simple relations. At present, our knowledge of the chromosomes of mammals is still too seanty to justify any generalization.

Particularly in domestic mammals, the problem of racial difference relating to the chromosomal features is of special interest and importance. The work done by the present author in this direction with the sheep, goat, cattle, pig and horse make it clear that there is neither evidence for polyploidy nor any kind of numerical differences of chromosomes among the varieties or races of animals within one and the same species (Makino $1943 \mathrm{~b}, \mathrm{c}, 1944 \mathrm{~b}$, d). Furthermore, the comparative investigation undertaken between the wild form and the domesticated variety yields a similar result. The chromosomal condition is quite identical in every respect of number and morphology, for example between the Norway rat and the white rat, the domestic swine and the wild boar, or the domestic cat and the wild cat (Makino 1942, 1946, 1952).

\section{The Karyotype}

The karyotypes of Japanese mammals made clear in these studies

T.S. Painter, 1925. Amer. Natur. 59: 335.

2 Matthey, R. 1948. Les Chromosomes des Vertébrés. Lausanne. 


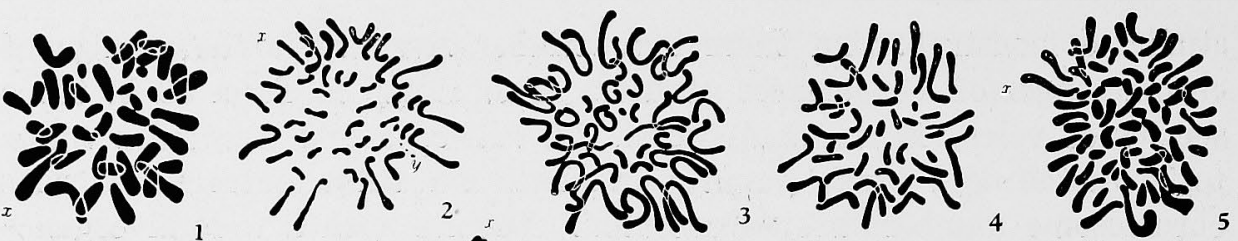

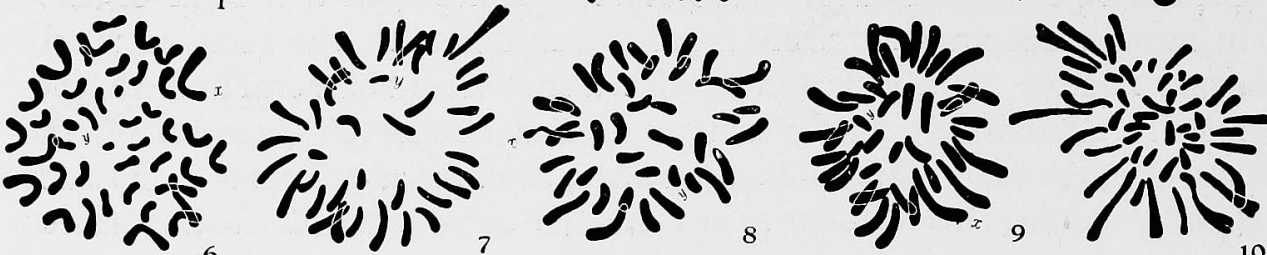

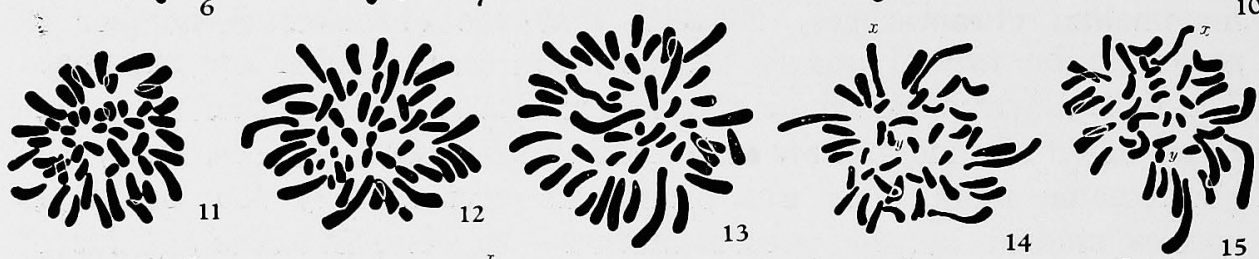

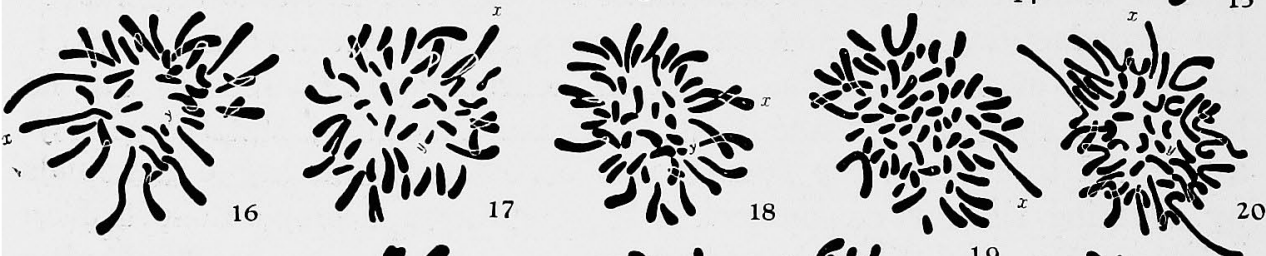

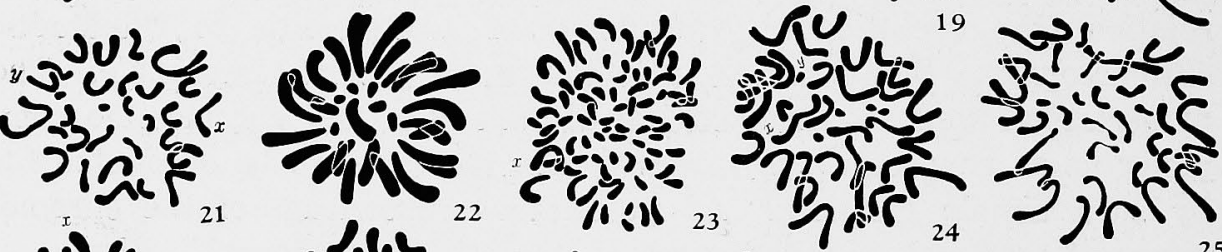

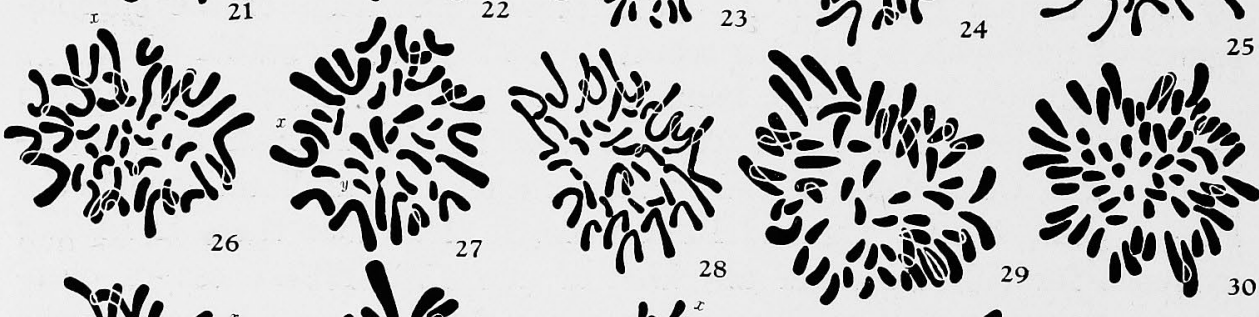

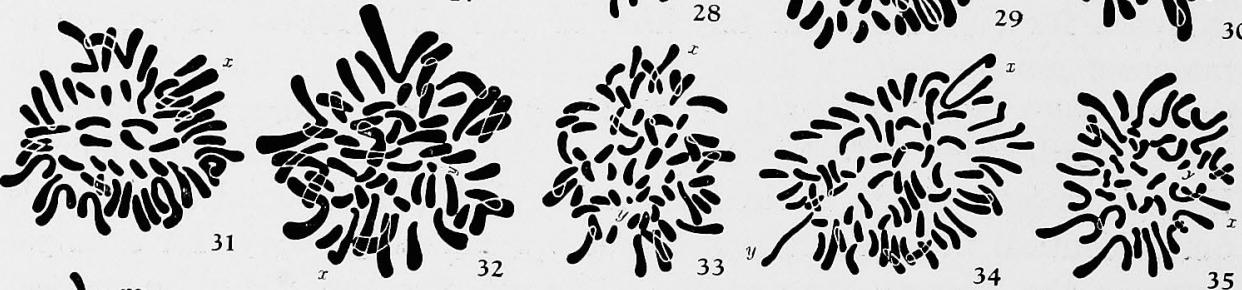

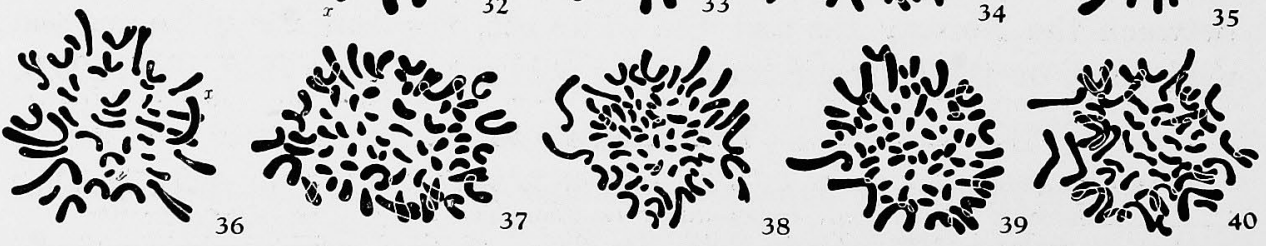

Figs. 1-40. All are spermatogonial groups, except Fig. 22 which is the female somatic 
are illustrated in the accompanying figures (Figs. 1-40). Reference to these figures shows that there are considerable variations of the karyotype from species to species, as was encountered in the case of the chromosome number. But, comparative observations indicate that there is a similarity or a close resemblance in the karyotypes of related species. Available examples on this point are seen in cases of Rattus, Mus, Apodemus, Microtus of the Rodentia, and in some carnivores and ungulates. The species belonging to Rattus, Apodemus and Mus are characterized by having chromosome complexes provided with rod-shaped elements, the constitution and morphology of which are characteristic to each species, respectively (Makino 1941, 1942, 1943a, 1949b, 1950c, 1951a, 1951c). The karyotype of Microtus consists of atelomitic chromosomes having V- and J-shape of various sizes, together with the smallest pair having grain-like appearance (Makino 1950a). The chromosome complements of the house cat, wild cat, lion and minks are nearly alike in their constitution, uniformly having 38 chromosomes which consist of various numbers of V's, J's, rods and dot-like elements (Makino 1947, 1952). The chromosomal features of some bovine animals such as cattle, zebu, and goat, closely resemble one another; each possesses 60 chromosomes in the diploid set, the constituent elements of which are all of the rod-type (Makino 1943c, 1944a, 1944d). The karyotypes of the horse, ass and mule are apparently alike in their constitution, each showing 66 chromosomes which consist of at least $12 \mathrm{~V}$ or J-shaped elements, the remainder being rod- and dot-like ones of varying sizes (Makino 1943b, 1944a, 1949a).

Some cytological data at hand seem to furnish some suggestive evidence as to the evolution of karyotype within a certain group or related species. For instance, the number and morphological character of chromosomes of the sheep are apparently different from those of the goat, but their karyological relationship is easily explicable by the mechanism of the formation of the V-shaped multiple chromosomes due to the union of rod-elements two by two (cf. Makino 1943e). The

complex ; camera-lucida drawings. The sex chromosomes are marked only in the cases in which their identification was possible. 1, Manis pentadactyla. 2, Phocoenoides dalli. 3, Pteropus dasymallus inopinatus. 4, Lepus cuniculus. 5, Cavia cobaya. 6, Myocastor coypus. 7, Mus musculus. 8, Mus molossinus. 9, Mus caroli. 10, Apodemus agrarius. 11, Apodemus semotus. 12, Apodemus speciosus. 13, Apodemus geisha. 14, Rattus norvegicus. 15, Rattus rattus. 16, Rattus los $€$ a. 17, Rattus fulv. coxinga. 18, Rattus conf. culturatus. 19, Micromys minutus takasagoensis. 20, Nesokia nemorivaga taiwanus. 21, Microtus kikuchii. 22, Tscherkia triton. 23, Canis familiaris. 24, Vulpes vulpes. 25, Fe'is domestica. 26, Felis leo. 27, Mustela itatsi. 28, Helictis subaurantiaca. 29, Bos taurus. 30, Bos indicus. 31, Bubalus buffelus. 32, Ovis artes. 33, Capra hircus. 34, Rangifer phylarchus. 35, Sus scrofa. 36, Sus vittatus leucomystax. 37, Equus caballus. 38, Equus asinus. 39, Mule. 40, Presbytis (Pithecus) entellus. 
number of chromosomes of Apodemus varies by species such as 46,48 and 50 , but this numerical variation is explicable by the evidence of the final disappearance of the smallest autosomal pair through gradual diminution (Makino 1951a). A similar phenomenon has also been encountered in Rattus (Makino 1943a).

In the light of the cytological investigations in connection with the racial difference of domestic mammals, it was concluded that, so far as the results obtained for the horse, sheep, goat, cattle and pig are concerned, the chromosome constitutions of these animals show nothing different according to the races or varieties, neither in the number nor in many morphological characters of the chromosomes (Makino 1943b, c, 1944a, b, d, 1946, 1949a). A quite similar result has also been gained in the comparative observations of chromosomes in domesticated animals and their wild forms or varieties. The results obtained for wild grey mice and white spotted tame mice, Norway rats and albino rats, the domestic swine and the wild boar, and the house cat and the wild cat, respectively prove that the chromosome constitutions of the domesticated forms of animals are apparently similar in all characters to those of the wild forms or wild varieties (Makino 1941, 1942, 1946, 1952). It is interesting to learn that the chromosomes of the domesticated forms undergo no visible shifting from those of the wild forms or varieties even after many years' artificial domestication and inbreeding.

The cytological characters, as mentioned above, show a wide variation among the mammals thus far studied. On the whole, there occur among them either the isomorphic karyotype which consists of simple rod-shaped constituents alone, or the polymorphic karyotype which contains certain numbers of V's, J's, rods and dot-like elements. The latter sort is found rather widely in all orders so far studied. The cytological data now at hand are not suitable as criteria in elucidating evolutionary relationship among mammals: their value as criteria of evolutionary significance must be tested by analysis of a more representative sample of the group - in all cases a wider cytological sampling of the included species should be made. But, wide diversity in chromosome number and in karyotype seems to suggest taxonomic diversity in mammals.

\section{Sex chromosomes}

Structure and mode of conjugation and separation of the $X Y$ complex in meiosis: The species here coming under study show the sex chromosome mechanism of the XY type in the male, except in a few cases not determined as yet. The morphological characters of both the $\mathrm{X}$ and $\mathrm{Y}$ chromosomes exhibit a tremendous variation by species, especially in size, shape and meiotic behavior, as shown in Figs. 41-77. The data now available on the shape and the mode of conjugation of the 
$\mathrm{X}-\mathrm{Y}$ chromosome observed at the first metaphase will be reviewed below under a few categories, followed by a consideration of their taxonomic implication.

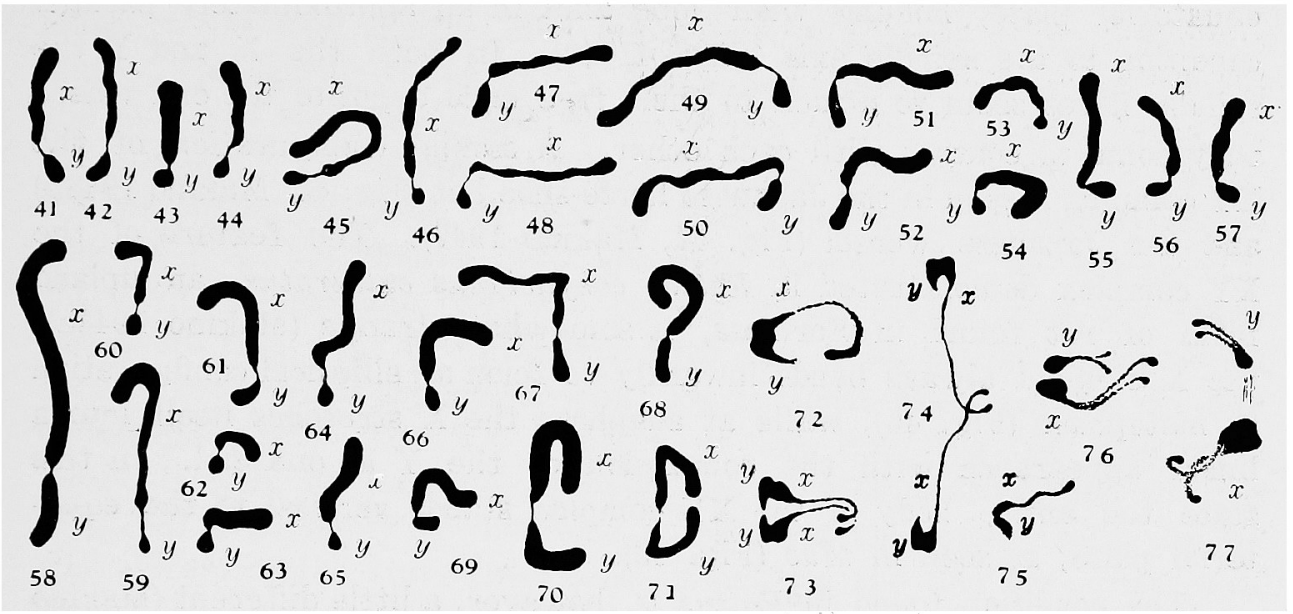

Figs. 41-77. All are the XY complexes at first metaphase, except Figs. 73, 74, 75 and 77. 41, Mus molossinus. 42, Mus musculus. 43, Rhinolophus ferrum-equinum nippon. 44, Mustela itatsi. 45-46, Rattus conf. culturatus. 47, Rattus norvegicus. 48, Rattus losea. 49, Lepus gichiganus ainu. 50, Nesolia nemorivaga taiwanus. 51, Equus caballus. 52, Equus asinus. 53, Ovis aries. 54, Capra hircus. 55, Bos taurus. 56, Bos indicus. 57, Buballus buffelus. 58, Manis pentadactyla. 59, Pteropus dasymallus inopinatus. 60, Presbytis (Pithecus) entellus. 61, Myocastor coypus. 62, Felis domesticus. 63, Phocoenoides dalli. 64, Sus scrofa. 65, Vulpes vulpes. 66, Felis leo. 67, Rattus fulv. coxinga. 68, Canis familiaris. 69, Cavia cobaya. 70, Rangifer phylarchus. 71, Microtus kikuchii. 72, Apodemus speciosus. 73, the same, early anaphase. 74, the same, telophase. 75, the same, second metaphase. 76, Apodemus geisha, meta-anaphase. 77, the same, first anaphase.

There is a group of mammals in which both the $\mathrm{X}$ and $\mathrm{Y}$ chromosomes are represented by the rod-shaped elements. Generally, the $\mathrm{X}$ is represented by one of the larger elements and the $Y$ is one of the smaller elements in the complement. Most species of the Muridae belonging to Mus, Battus, Apodemus, Nesokia and Lepus (Figs. 41-42, 4550, 72-77), the Japanese horse-shoe bat (Rhinolophus ferrum-equinum nippon), Japanese weasel (Mustela itatsi), Formosan badger (Helictis subaurantiaca) (Figs. 43-44), and some ungulate mammals such as the horse, ass, sheep, goat, cattle, zebu and water-buffalo (Figs. 51-57) were found to possess the XY chromosomes of this category. As understood by reference to the annexed figures (Figs. 41-57), a striking variation occurs in size and shape of both the $\mathrm{X}$ and $\mathrm{Y}$ elements from species to species.

Here noticeable, is the mode of conjugation occurring between the $\mathrm{X}$ and $\mathrm{Y}$ at the first meiosis which is also not uniform by species. From the cyto-taxonomic view-point, the mode of conjugation between the $\mathrm{X}$ and $\mathrm{Y}$ is of special interest, and it appears to provide a cyto- 
taxonomic character. In the genus Mus (Makino 1941), the three species under study show a uniform feature in that the $\mathrm{X}$ and $\mathrm{Y}$ at the first metaphase always stands, in a linear connection, almost vertical to the equatorial plate, holding their long axes in an approximately parallel condition to the spindle axis (Figs. 41-42). In both the $\mathrm{X}$ and $\mathrm{Y}$ the spindle fibres seem to attach to their free ends opposite the end where they come to contact with each other. A similar configuration of the XY complex is seen in the Japanese horse-shoe bat (Fig. 43, Makino 1948b) and the Japanese weasel (Fig. 44, Makino 1947). The feature of the $\mathrm{XY}$ complex demonstrated in Rattus confucianus culfuratus, an upland form of rat found in Formosa, is somewhat strange (Makino 1943a): the $\mathrm{X}$ element always bends inwardly to form an elliptical configuration at metaphase (Fig. 45), while at anaphase the $X$ stretches itself into a linear appearance with the companion of the $Y$ at one end. In this. state the entire body of the XY complex stands vertical to the equatorial plate, as seen in Mus (Fig. 46).

The condition found in Rattus is, however, a little different (Makino 1943a). It is seen in $R$. norvegicus, $R$. ratius and $R$. losea that the $\mathrm{X}$ element lies horizontally in the equatorial plate with its long axis parallel thereto stretching over the whole length and directing the inner end of its spindle fibre locus towards the centre of the spindle (Figs. 4748). To the inner extremity of the $X$, the $Y$ comes in contact. The $\mathrm{Y}$ stands perpendicular to the equatorial plate with the spindle fibres at its free end. The sex-chromosomes of Lepus (Fig. 49), Nesokia (Fig. 50) and some hoofed animals like the horse, ass, sheep and goat (Figs. 51-54) are characterized by assuming a similar structural configuration (Makino 1943b, c, 1944c). The XY complex of the cattle, zebu and waterbuffalo is, on the other hand, clearly distinguishable from the above in that it assumes a remarkable modified form in conjugation; the $\mathrm{X}$ element always stands nearly vertical to the equatorial plate, holding its long axis parallel to the spindle axis, while the $\mathrm{Y}$ lies horizontally in the equatorial plate with its long axis lying parallel to the latter, connecting end-to-end with the $\mathrm{X}$ (Figs. 55-57). The condition of the $\mathrm{X}$ is nearly identical to that in Mus, but the configuration of the $\mathrm{Y}$ is characteristic for the three species of bovine animals (Makino 1944d). The spindle fibres possibly attach to the free end of the $X$ and to the inner proximity of the $\mathrm{Y}$ where it comes in contact with the $\mathrm{X}$.

There is another group of mammals which are characterized by having an $\mathrm{X}$ chromosome of atelomitic nature, being $\mathrm{J}$ or $\mathrm{V}$ in shape. In the pangolin, Manis pentadactyla (Fig. 58; Makino \& Tateishi 1951d), the Okinawa fruit bat, Pteropus dasymallus inopinatus (Fig. 59; Makino 1948b), a species of monkey, Presbytis (Pithecus) entellus (Fig. 60) and the nutria, Myocastor coypus (Fig. 61; Makino 1947), the X chro- 
mosome is of submedian or subterminal structure assuming a remarkable J-shape. At the first metaphase, the $\mathrm{X}$ is placed so that its longer arm connected with the $\mathrm{Y}$ at its extremity is vertical to the equatorial plate, while the shorter arm lies generally parallel to the equatorial plate. The spindle fibres of the $\mathrm{X}$ apparently attach to the point where the long and short arms join, while in the $\mathrm{Y}$ they possibly attach to its free end. The house cat (Fig. 62; Makino \& Tateishi 1952), porpoise, Phocoenoides dalli (Fig. 63; Makino 1948a), pig (Fig. 64; Makino 1944b) and fox (Fig. 65; Makino 1947) are also characterized by having a Jshaped $\mathrm{X}$ chromosome, but are clearly differentiated from the above forms in that the $\mathrm{X}$ conjugates with the $\mathrm{Y}$ at the extremity of its shorter arm, while its longer arm lies in most cases parallel to the equatorial plate. The XY complex of the lion (Fig. 66; Makino \& Tateishi 1952), Rattus fulv. coxinga (Fig. 67; Makino 1943a) and the dog (Fig. 68) is probably of the same nature, but the latter forms can be well differentiated from the above animals by the fact that they have the $\mathrm{X}$ chromosome with a little longer short arm. The feature of the $\mathrm{XY}$ complex in the guinea pig, Cavia cobaya (Fig. 69; Makino 1947) is also interesting: the $\mathrm{X}$ element bends inwardly at two joints so as to give an elliptical configuration, and conjugates at its inner extremity with the Y. Particularly noticeable is the feature of the $Y$ chromosome which lies horizontally in the equatorial plate, with its long axis parallel to the latter. The guinea pig is thus differentiated from the others by such a remarkable configuration of the $\mathrm{XY}$ complex as mentioned above.

In the two species of Microtus studied by the author (Makino 1950a), there has been demonstrated another morphological type of the sex chromosomes. It was shown that the $\mathrm{X}$ and $\mathrm{Y}$ are represented by atelomitic $\mathrm{V}$ - and $\mathrm{J}$-shaped elements, respectively, and that there is little difference in size between the two components. In conjugation, the shorter arm of the $\mathrm{X}$ comes to connect with the shorter arm of the $Y$ at their extremities; the shorter arms of both elements coming in connection are vertical to the equatorial plate, while the longer arms remain free from one another (Fig. 71). Probably, the spindle fibres attach to the point where the long and short arms join together in both the $\mathrm{X}$ and $\mathrm{Y}$. It is further interesting to note that in the reindeer, Rangifer phylarchus, a simulating feature of the XY complex was observable, where the $Y$ element is again unusually large compared with the $\mathrm{X}$. But in this cases, the fibre attachment of the $\mathrm{Y}$ is terminal; probably the spindle fibers attach to the inner end of the Y. (Fig. 70; Makino 1944a, 1949a).

In all the foregoing cases, the separation of the XY complex takes place without exception in the first division, so that the latter division is reductional for the segregation of the $\mathrm{X}$ and $\mathrm{Y}$. Data on the anaphase 
segregation of the XY complex in the first division, gathered from Mus and Rattus, unexceptionally show disjunction of the $\mathrm{X}$ from the $\mathrm{Y}$ (Makino 1941, 1943a). The pre-reductional segregation of the XY complex gives rise to two different kinds of secondary spermatocytes, one with the $\mathrm{X}$ element and the other with the $\mathrm{Y}$. No exceptions to this behavior have been found among cases under observation.

The field mice belonging to the genus Apodemus (Muridae) stand in striking contrast to the above-mentioned forms of mammals: They show unusual features of sex chromosomes both as to structure and behavior in meiosis and as to mode of segregation in the meiotic divisions, characterized by the post-reductional separation of the sex chromosomes (Makino 1951a). So far as the five Asiatic species of Apodemus studied by the author are concerned, both the $\mathrm{X}$ and $\mathrm{Y}$ chromosomes manifest at the first metaphase a longitudinal structural differentiation into two different parts, the proximal sections being made up of heterochromatin and the distal sections of euchromatin. The proximal heterochromatic sections give a densely stained massive appearance and lie always in close contact with each other, while the distal euchromatic sections take the form of lightly thin threads, unequal in length, extending freely out of the former. Thus, the XY complex is made up of two entities, highly different in appearance: the $\mathrm{X}$ is represented by a condensed massive body carrying an elongated thin arm and the $Y$ by a similar body provided with a very short arm, the two being associated sideby-side at their proximal massive parts, but having the two thin arms free and unpaired (Fig. 72). At metaphase the XY complex manifests a pronounced longitudinal split, either in the proximal massive bodies or in the diffused arms, along a plane parallel to the equatorial plate, which suggests their equational separation. The results of statistical observation indicate that the separation of the XY complex is always post-reductional in Apodemus speciosus, A. agrarius var. insilaemus, $A$. agrarius, and $A$. semotus, the XY complex splitting without exception into two equal halves in the first division, quite identical in shape and and size (Figs. 73-74), while in the second division the $X$ always disjoins from the $\mathrm{Y}$ (Fig. 75). In striking contrast to the above four species, $A$. geisha shows an exceptional feature that the XY complex undergoes a reductional separation in the first division, the $\mathrm{X}$ and $\mathrm{Y}$ passing to opposite poles (Figs. 76-77).

It is interesting to find that in accordance with the taxonomical kinship to Apodemus, Micromys minutus takasagoensis shows the postreductional behavior of the $\mathrm{XY}$ complex in the meiotic divisions.

Behavior of the sex chromosomes in the meiotic prophase: The behavior and morphological changes of the sex chromosomes were followed in Mus musculus, Rattus norvegicus and Apodemus speciosus, 
from their appearance in the early stage of the growth period of the spermatocyte up to the metaphase stage of the first division (Makino 1941, 1951a). The observations on Mus and Rattus yielded similar results as follows: The $\mathrm{X}$ chromosome assumes the form of a chromosome vesicle during the growth period. From the late pachytene through to the commencement of diakinesis the $\mathrm{X}$-vesicle completely associates with the nucleolus into a single huge mass of squarish oblong shape, thus forming the so-called amphinucleolus. In the later part of the diplotene stage the $\mathrm{Y}$ chromosome comes to lie in the proximity of the $\mathrm{X}$ vesicle. The $\mathrm{X}$ and $\mathrm{Y}$ elements remain as separate entities during the early part of the growth period, having absolutely no relationship to each other. The conjugation of the $\mathrm{X}$ and $\mathrm{Y}$ takes palce in the late diplotene stage. Their conjugation is of the most perfunctory character and made by an end-to-end connection. There exists not even a slight trace of either side-by-side conjugation in the form of chromatin threads, or of the formation of chiasmata between the $\mathrm{X}$ and $\mathrm{Y}$. Obviously, the data at hand thus failed to yield cytological evidence of crossing-over between the $\mathrm{X}$ and $\mathrm{Y}$ elements (Makino 1941).

The nuclei of the meiotic prophase of Apodemus are also characterized by the formation of an amphinucleolus involving the association of the XY complex with the nucleolus. The XY complex is in close association with the nucleolus from leptotene to early diakinesis. Through these stages the proximal parts of the $\mathrm{X}$ and $\mathrm{Y}$ remain heteropycnotic in the form of two condensed masses, being in contact with each other, but having two thin thread-like arms free and unpaired. The configuration of the XY complex in meiotic prophases closely resembles that observable in the equatorial plate of the first division. The association of the XY complex with the nucleolus seems to persist until late diakinesis. The dissociation of the XY complex from the nucleolus takes place at late diakinesis.

The $\mathrm{X}$ and $\mathrm{Y}$ elements come together in side-by-side association only in their proximal heterochromatic portions, while their thin arms remain free. Further, the proximal heterochromatic sections of the $\mathrm{X}$ and $Y$, which alone are associated during meiosis, were proved to remain always as heteropycnotic bodies in meiotic prophase nuclei, without any uncoiling into chromonema threads. This evidence excludes the possibility of segmental pairing in the proximal sections of the $\mathrm{X}$ and $\mathrm{Y}$, and the formation of any chiasmata between them during the meiotic prophases (Makino 1951a). Probably, the association between the $X$ and $\mathrm{Y}$ might be accounted for by a mutual attraction which brings the two elements together, coupled at the same time with the cohesive nature of heterochromatin. 


\section{Summary}

In this paper the distinguishing cytological characters, including chromosome number, karyotype and sex chromosomes, especially their size, shape and type of conjugation in meiosis, have been reviewed, based on the author's own data in 49 species of Asiatic mammals representing eight eutherian orders. The results are summarized in Table 1.

The cytological data now at hand seem not to permit any conclusion as to the evolution of karyotype in mammals. The numerical as well as morphological diversities of chromosomes in mamals are very wide, and at present our knowledge of the mammalian chromosomes is still too scanty to warrant any generalizing remarks, regarding the basal or fundamental chromosome number, or the evolutional change of karyotype.

The species here under study uniformly show the sex chromosome mechanism of the XY type in the male. Striking variations occur in size and shape of both the $\mathrm{X}$ and $\mathrm{Y}$ chromosomes from species to species. Special cyto-taxonomic interest attaches to the type of conjugation occurring between the $\mathrm{X}$ and $\mathrm{Y}$ and the mode of their segregation in meiosis; they also vary by species, but appear on the basis of present study to provide interesting cyto-taxonomic characters.

\section{REFERENCES PERTAINING TO THE MAMMLIAN CHROMOSOMES PUBLISHED BY THE WRITER}

Makino, S. 1941. Studies on the murine chromosomes, I. Cytological investigation of mice, included in the genus Mus. Jour. Fac. Sci. Hokkaido Univ. VI, 7 : $305-380$.

- 1942. Ditto, II. Morphological comparison of the chromosomes between the wild form and the domesticated variety of Rattus norvezicus Berk. Ibid. 8: 31-43.

- 1943 a. Ditto, III. A comparative study of chromosomes in five species of Rattus. Jour. Fac. Sci. Hokkaido Univ. VI, $9: 19-57$.

- $1943 \mathrm{~b}$. The chromosomes of the horse (Equus caballus), (Chromosome studies in domestic mammals, 1). Cytologia $13: 26-38$.

- $1943 \mathrm{c}$. The chromosome complexes in goat (Capra hircus) and sheep (Ovis aries) and their relationship. (Ditto, II). Cytologia $13: 39-54$.

- $1943 \mathrm{~d}$. Oocyte chromosomes of Rattus norvegicus and Clethrionomys rufocanus bedfordiae. (With E. Sigemoro). Med. \& Biol, 4: 76-78.

- 1944 a. A contribution to the study of the chromosomes of domestic mammals. Zool. Mag. (Tokyo), 56: $8-15$.

- $1944 \mathrm{~b}$. The chromosome complex of the pig (Sus scrofa). (Chromosome studies in domestic mammals, III). Cytologia 13: 170-178.

- $1944 \mathrm{c}$. Studies on the murine chromosjmes, IV. The karyotypes of the mole-rat and the harvest-mouse. Cytologia $13: 237-245$.

- $1944 \mathrm{~d}$. Karyotypes of domestic cattle, zebu and domestic water-buffalo. (Ditto, IV). Cytologia 13: 217-264.

- 1946. On the karyological relationship of the domestic swine and the Japanese wild boar. La Kromosomo 1: 12-17. 
- 1947. Notes on the chromosomes of four species of small mammals. (Chromosome studies in domestic mammals, V). Jour. Fac. Sei. Hokkaido Univ. VI, 9: 345-357.

- 1948 a. The chromosomes of Dall's porpoise, Phocoenoides dalli (True), with remarks on the phylogenetic relation of the Cetacea. Chromosoma $3: 220-231$.

- 1948 b. A study of the chromosomes in two species of bats (Chiroptera). Biol. Bull. 94: $275-282$.

- 1949 a. A review on the chromosomes of domestic mammals. Jap. Jour. Zootech. Sci. 19 : 5-15.

- 1949 b. A chromosomal survey in some Asiatic species of the Muridae, with special regard to the relationship of the chromosomes upon taxonomy. Cytologia 15: 153-160.

- 1950 a. Studies on murine chromosomes, VI. Morphology of the sex chromosomes in two species of Microtus. Ann. Zool. Japon. $23: 63-69$.

- 1950 b. Contribution of the sex chromosome in an intersex goat. Papers from the Coordinating Committee for Research in Genetics, 1: 1-3.

- 1950 c. On the chromosomes in five Asiatic species of Apodemus. Ibid. 1: 79-84.

- $1950 \mathrm{~d}$. On the degeneration of germ cells in experimental cryptorchid testes of the white rat. (With T. Nakamura). Cytologia 16: 27-36.

- 1951 a. Studies on the murine chromosomes, V. A study of the chromosomes in Apodemus, especially with reference to the sex chromosomes in meiosis. Jour. Morph. $88: 93-126$.

- 1951 b. Karyotype of Tscherkia triton (Muridae-Cricetinae). La Kromosomo 8: 311-312.

- 1951 c. A study of the chromosomes in a mixed strajn of the albino rat and the wild Norway rat, in connection with the question of the unusual chromosomal condition reported by Swezy (1928). (Studies on murine chromosomes, VII). La Kromosomo 9-10 : 356-359.

- $1951 \mathrm{~d}$. Notes on the chromosomes of the pangolin (Manis pentadactyla). (Edentata). (With S. Tateishi). Jour. Fac. Sei. Hokkaido Univ. VI, Zool. 10 : 318-322.

- 1952. A comparison of the chromosomes in the lion, Chinese leopard cat and house cat. (With S. Tateishi). Jour. Morph. (In press). 